\title{
On Technology Transfer
}

\author{
George Varghese \\ Microsoft Research \\ Redmond, WA, USA \\ varghese@microsoft.com
}

I agree with the editors of this series that technology transfer from academia occurs in a variety of ways with different tradeoffs. I describe, to the best of my recollection, some of my experiences with ideas that originated or were described in academic papers, from Deficit Round Robin to Conga.

\section{DEFICIT ROUND ROBIN}

Deficit Round Robin (DRR) began when M. Shreedhar, then a Masters student at Washington University, and I read the seminal paper on Weighted Fair Queuing (WFQ) by Demers, Keshav and Shenker. At the time, it seemed to us (wrongly, it turns out) that WFQ was only about fairness; if so, we felt the algorithm was too complex to implement in hardware. Standard or weighted round-robin was easy to implement but was unfair for variable-sized packets.

We found we could restore fairness by adding a quantum to each queue in Round-Robin and by remembering the "deficit" that a queue did not use. After adding a proof of fairness and a few simulations we submitted a SIGCOMM paper which was accepted. The SIGCOMM talk was couched in terms of a mythical loading dock at which parcels were loaded, and for which slicing parcels into bits was unacceptable. There we thought the matter would end.

However, in the fullness of time, Fred Baker, who I had known from DEC days, came to visit Washington University. I cannot remember why he visited, but it certainly was not to acquire technology. Fred now worked for Cisco.

Fred described a problem they had at Cisco with large flows doing file backups hogging output links, which in turn slowed down interactive traffic like Telnet. I told Fred about the DRR paper because I thought it might help.

I surmise that Fred evangelized the idea within Cisco. He later told me that Cisco had already implemented Weighted Round Robin but with carry-over done incorrectly. Soon every Cisco router began to advertise a variant of DRR called MDRR. Next, Raj Yavatkar wrote DRR code for Microsoft and Intel. After that somehow DRR was everywhere.

I remember having strained conversations later with researchers who worked on cleverer router scheduling algorithms with more intricate proofs. It was clear they thought of DRR as a bit of a fraud, a small variant on weighted round robin, an intellectual disgrace.

I am sure they were right; but in defense, perhaps one needs simple algorithms to scale to terabit speeds. Sorting flow timestamps, as required for WFQ is hard (but not impossible), and is not needed if fairness is the only goal. Of course, with the work of Parekh and Gallager, we know that if you want latency bounds, DRR is not very effective.

DRR taught us the virtues of simplicity, and having models of hardware complexity. It also taught us that having no university patents was a good thing. Fred checked this point discreetly. I could answer in the quaint legal phrase that "there were no impediments" - almost like a marriage banns!

Now there are hundreds of good ideas in academic papers that are never picked up. What does one do to produce a rabbit in the hat like Fred Baker? I have no answer, except to commend you to grace, sheer undeserving favor, beyond our control.

\section{IP LOOKUPS}

Around the same time, IP Lookups was considered too slow. Cisco and others were proposing MPLS to fix the problem. This seemed egregious to us. V. Srinivasan (Cheenu) was working with me as a graduate student.

The best data structure for IP lookups at the time was a Patricia trie. Patricia tries were good for exact lookups but less desirable for prefix lookups: lookup was slow because it proceeded 1-bit at a time, and the use of a so-called skip count for compression sometimes led to backtracking.

What if we removed skip counts and worked multiple bits at a time, analogous to the way B-trees use high degree trees to reduce tree height? 
We added a few algorithmic flourishes such as dynamic programming to compute optimal node degrees to balance storage and time. In retrospect these embellishments were less useful in practice; but they probably were essential for publication at a serious conference.

Jon Turner, the thoughtful chair of my department, told us that he would pay $\$ 10,000$ dollars for a patent. In those days that was a big sum. But there was a codicil. I had go to companies to "sell" the patent.

That initially sounded daunting. Surely being a professor was sitting in my office, thnking deep thoughts. But I reluctantly agreed.

One irony of the patent submission process is that our SIGCOMM submission omitted several technical details. This justly provoked the referees' ire. Fortunately, the patent submission process finished quickly and we were able to rush the paper to SIGMETRICS.

By then Marcel Waldvogel had visited Washington University. With Jon Turner, we had a second patent on binary search on prefix lengths which was more intellectually satisfying.

We decided to bundle the patents together. I contacted industry to market the patents. Everyone seemed to be building routers in those days, and so many companies, small and large, came to us.

Andy Bechtolsheim, then at Cisco after founding Granite Systems, called after we sent the ideas to Cisco. He told me that the multibit trie idea had already been done at Cisco, but they would not interfere with our patents if we did not interfere with theirs. Binary search on prefix lengths was new, but less useful to Cisco. This was disconcerting but it was a good reminder that ideas are often invented concurrently.

We used a non-exclusive model for licensing which I think was a good idea. We had a very helpful licensing officer called Ed Fickensher. It took a little time to educate him that our patents were not exactly equivalent to a miracle drug, and had to be priced accordingly. Once that happened things moved quickly.

We learned an important lesson about technology transfer. One must convince both the highest decision makers as well as the engineers responsible for implementation. Without support from the former, there is no power to make decisions; without support from the latter, there is initial enthusiasm but it quickly subsides into silence.

For example, at one software company there was an issue implementing multicast. Fortunately, Cheenu worked hard and shipped some code modifications. This direct interaction was crucial and instructive.

\section{NETSIFT AND CONGA}

After research in worm detection with Sumeet Singh, Stefan Savage and Cristi Estan, we started a company called NetSift. The signature extraction patent was li- censed by UCSD to the company. The university was less interested in licensing revenue than in a potential acquisition or an IPO. After NetSift was acquired by Cisco, the NetSift team worked dligently at Cisco to build a chip to embody the ideas. As far as we know, the chip was never used.

A classic physics problem asks for methods of estimating the height of a building given a stopwatch. After a number of clever and strenuous methods involving dropping objects and casting shadows, the most painless method is to go to the building supervisor and say, "I have a very nice stopwatch you mght like. Could you tell me the height of your building?"

In the same vein, I recently worked on a problem with Tom Edsall at Cisco and my student Terry Lam. Later, Mohammed Alizadeh joined Cisco and made crucial breakthroughs. Tom used a variant of these ideas, reported in the Conga paper, in a Data Center router. If technology transfer is the goal, then perhaps joint research with industry is the simplest route.

\section{CONCLUSION}

The DRR experience suggests that "giving away" technology facilitates technology transfer while the IP Lookup experience suggests that obtaining patents and pricing them reasonably, makes companies value even small inventions. The apparent contradiction is resolved by realizing that there are many paths to technology transfer.

Starting a company allows an idea to be more fully developed in context, while working with standards bodies allows the community to gather around an idea.

Since no approach is guaranteed success, it seems best to enjoy each attempt as an adventure, with the benefit of at least learning about new, real problems on the frontiers of research.

I summarize potential lessons based on my limited experience:

1. Being contrarian: Research that goes against industry trends may win you an audience in industry.

2. Simplicity: Simplicity may not be valued in academia but is often essential in transferred technology.

3. Licensing: The IP lookup patent and licensing model may be dated and not easy to replicate today.

4. Rewards: Intellectual Property Rights and a price can be part of transfer, but greed is poisonous (Fred Baker).

4. Influencers: Do not disregard either engineers or managers as influencers.

5. Companies: Founding companies, despite acquisition, may not lead to a change in practice.

6. Partnering: A number of companies offer university reseach programs. If the IP issues can be navigated, these offer the most accessible path to technology transfer working directly with engineers designing products. 